\title{
Notas de lectura acerca de El rey duerme
}

Miriam Viviana Gáratea

\section{Resumen}

La frecuentación de textos fundadores es una constante en la ensayística de Juan Villoro (Ciudad de México, 1956). En El rey duerme, crónica hacia Hamlet (2008), el escritor pone en escena un singular acercamiento a la pieza homónima de Shakespeare. El artículo propone una lectura de ese texto en torno al siguiente conjunto de cuestiones: a) las interferencias y tensiones existentes entre crónica $y$ discurso ensayístico; b) las varias figuraciones de la relación maestro/discípulo; c) el diálogo polémico entablado con la interpretación de Harold Bloom (Shakespeare: The Invention of the Human, 1998) y las estrategias textuales implementadas para ese fin; d) el desplazamiento interpretativo propuesto a partir del Hamlet traducido al español por Tomás Segovia (2002) y del último cuento de Jorge Luis Borges (1985).

Palabras clave: relecturas de Hamlet; crónica, discurso ensayístico y traducción; Juan Villoro. 
La frecuentación de textos fundadores es una constante en la ensayística de Juan Villoro (Ciudad de México, 1956). Singulares acercamientos a títulos del canon europeo - El Quijote, una lectura fronteriza (2008), Lo que hay en un nombre: el Emilio de Rousseau (2008), Las ataduras de la libertad: Goethe y Las afinidades electivas (2008) -, o a obras y autores claves para la ficción mexicana e hispanoamericana del siglo XX - Lección de arena: Pedro Páramo (2001), Monterroso: el jardín razonado (2001), La fisonomía del desorden: de El pozo a Los adioses (2008) -, constituyen un núcleo importante de su producción. De una producción que no es ajena, por otra parte, a la incursión en una práctica adyacente, ni a la reflexión sobre la misma: la traducción, actividad en la que también comparecen nombres expresivos o que han devenido expresivos a lo largo del último siglo. Baste mencionar como ejemplo tan sólo tres de los escritores vertidos por Villoro del alemán al español: Lichtenberg, Goethe, Schnitzler.

Ni el ejercicio de la traducción, ni la copiosa producción ficcional de Villoro, que cuenta con cuatro novelas, seis volúmenes de cuentos y varias narrativas infanto-juveniles publicadas, además de algunas piezas teatrales, han sido obstáculo, como es sabido, para el despliegue de otro frente de actividad a menudo emparentado con sus relatos y su ensayística: la crónica. Es en el cruce de esos géneros que se sitúa El rey duerme. Crónica hacia Hamlet (2008), escrito compilado en un volumen que adopta como título, precisamente la traducción alternativa propuesta por Tomás Segovia (España, 1927/2011) para el cristalizado "he ahí el dilema", o "ésa es la cuestión", del monólogo hamletiano: De eso se trata. Ensayos literarios (2008). Y “de eso se trata", efectivamente; eso ejercita,

${ }^{1}$ Restituyo la cronología del título homónimo de Bloom en las ediciones inglesa y española, dato importante para las consideraciones que serán realizadas a continuación: Shakespeare: The Invention of the Human (1998); Shakespeare, la invención de lo humano (2001), traducción de Tomás Segovia. La edición en portugués data del a ño 2000 (traducción de José Roberto O’Shea). pone a prueba, intenta, la palabra de Villoro: reactivar desde distintas zonas el clásico de Shakespeare - para lo cual habrá de pleitearle a Bloom el presumido monopolio de La invención de lo humano ${ }^{1}$ releyendo el clásico en otras claves, confrontándolo con sus avatares en otras coyunturas, en otra lengua, en otras literaturas, con otras reinvenciones.

\section{I}

En el prólogo a De eso se trata, Villoro (2008, p.7) explicita su concepción del ensayo de escritores como una práctica 
${ }^{2}$ La doble gestión de los escritos de Juan Villoro en el ámbito editorial de lengua española, práctica que constituye una de las escenas del "más acá" (WEINBERG, 2017, p. 19), del horizonte contextual a ser llevado en consideración, merecería un estudio pormenorizado que excede el propósito del presente trabajo. Baste mencionar la constante publicación de sus textos en una red de editoras menores, generalmente con sede en diversos países de latinoamérica (Diego Portales, de Chile, Interzona, de Argentina, Almadía y Sexto Piso, de México) y su difusión, generalmente ulterior, a través de grandes sellos españoles, en especial Anagrama y Seix Barral. que al "ensayar sobre los otros ofrece una confrontación más indirecta pero más sincera" que las fabulaciones acerca de la propia obra, como suerte de "strip-tease al revés" donde la subjetividad del escritor/ensayista se muestra por lo que le "pone encima" al otro en el acto de la lectura. Pero lo considera también una puesta en relación con el otro y lo otro (el mundo, el texto, el lector), ya que quien practica el ensayo "no es el motivo central de la expedición" (Ibidem, p. 8). Ese vaivén ya había sido consignado en el prólogo a su primer volumen de escritos ensayísticos, Efectos personales (2001), y remite a una postura en sintonía con varios de los textos que se han tornado clásicos sobre el género (LUKÁCS, 1974; ADORNO, 2003; BENSE, 2014; STAROBINSKI, 2011, entre otros), bien como a reflexiones más recientes sobre su desarrollo en el continente (GIORDANO, 2005; WEINBERG, 2007, 2017; OLMOS, 2015, 2017). Del mismo modo, en la caracterización del ensayista como "viajero" cuya excursión es "ajena a las imposiciones", como alguien que "conecta libremente saberes dispersos" con el propósito de "razonar sus fervores" o "argumentar sus pasiones" (VILLORO, 2008, p. 8-9), pueden leerse otros tantos topoi que han devenido lugares consensuales en relación al discurso ensayístico: su forma fragmentaria, abierta, inconclusiva, su estatuto alterno en relación a la supuesta cientificidad de la crítica literaria, el valor atribuido al afecto como desencadenante de la lectura/escritura.

Refiriéndose a la presencia de este último aspecto en su primer libro de ensayos, Fazio (2010, p. 24) señala que la discursividad de Villoro asume con frecuencia "la forma del recuerdo y esto implica un doble movimiento: la escritura como recuperación, lo anecdótico como invención". La afirmación es válida para pensar El rey duerme, pero debe agregársele un elemento complicador (enriquecedor), manifiesto en el título: crónica hacia Hamlet. Por una parte, la doble inscripción reenvía a la pequeña historia de un ensayo redactado, a diferencia de los demás, tardía y expresamente para el volumen en cuestión. En la Noticia Bibliográfica final, Villoro atribuye el origen de De eso se trata a la iniciativa del director de publicaciones de la Universidad Diego Portales, sello responsable por la primera edición, del 2007, republicada al año siguiente en Anagrama² Matías Rivas propone realizar una selección de "ensayos literarios que se encontraban dispersos en diferentes periódicos 
y revistas o que habían prologado obras de otros autores" (VILLORO, 2008, p. 347). La preparación del libro suscita un rico intercambio de e-mails con Andrés Braithwaite, a cuyo cargo se encuentra la ejecución del proyecto:

De eso se trata estaba a medio camino cuando hablé con Braithwaite sobre la procedencia del título [del libro] y me instó a escribir un texto sobre Hamlet, tema que había rehuído con escrúpulo después de leer espléndidos ensayos al respecto. Braithwaite argumentó con pericia hasta que su iniciativa pareció una ocurrencia mía: más que un ensayo acerca de un tema canónico, escribiría la crónica hacia esa pieza inagotable. (VILLORO, 2008, p.347)

Y, en efecto, la andadura de El rey duerme puede leerse como la crónica de sí mismo, como el relato del proceso conducente a la escritura de un texto cuyo resultado el lector tiene ante los ojos. En esa estructura, la recuperación/invención de otra anécdota personal enmarca el núcleo ensayístico situado en la zona intermedia de esa crónica/ensayo o crónica de un ensayo (volveré de inmediato sobre esta cuestión).

No obstante, la presencia de la crónica y del cronista en este escrito debe considerarse en una acepción más restrita, en su remisión a un género situado en "la encrucijada de dos economías, la ficción y el reportaje" (VILLORO, 2006, p. 1), de dos esferas de actuación, la literatura y el periodismo:

De acuerdo con el dios al que se debe, la crónica trata de sucesos en el tiempo. Al absorber recursos de la narrativa, la crónica no pretende "liberarse" de los hechos sino hacerlos verosímiles a través de un simulacro, recuperarlos como si volvieran a suceder con detallada intensidad. (VILLORO, 2006, p.1)

La observación puede auxiliar en la lectura de la "crónica hacia esa pieza inagotable" que es el Hamlet de El rey duerme.

\section{II}

Resulta necesario citar por extenso la abertura del texto de Villoro

A fines de 1993 concluí en la UNAM un curso sobre "la idea de la Historia en la novela mexicana", dedicado a explorar las tensiones que la narrativa establece con los hechos. El siguiente semestre daría el mismo curso en la Universidad de Yale. 
Una engañosa euforia dominaba México en diciembre de 1993. El tratado de libre comercio con Estados Unidos y Canadá entraría en vigor el 1 de enero. Para muchos, así se anunciaba el ingreso al anhelado "primer mundo". Mi viaje a Yale tenía que ver con esa circunstancia: el presidente de la universidad se sorprendió de que no hubiera una cátedra sobre un país que influía cada vez más en la vida cotidiana de Estados Unidos y sugirió que se impartieran dos semestres de literatura mexicana. Margo Glantz se hizo cargo del primero y yo del segundo ¿Terminaba la época de los "espaldas mojadas" que trabajaban ilegalmente en los campos de algodón para pasar a los "cerebros mojados" que disertarían en las universidades? Estábamos ante otro espejismo de la relación entre México y Estados Unidos. La realidad era distinta: mientras las botellas de champagna se enfriaban en el Palacio Nacional para celebrar el tratado de libre comercio, los indios chiapanecos aguardaban que terminara la Misa de Gallo del 31 de diciembre para iniciar su rebelión.

Antes de que eso sucediera, me despedí de mis alumnos en la Facultad de Filosofía y Letras. Caminaba por el campus rumbo a mi coche cuando fui alcanzado por una alumna. Sobrevino uno de esos encuentros entre quienes sólo se han visto en un salón de clases y carecen de toda familiaridad. Ella quería decirme algo que no me dijo, y comentó que acababa de entrar a terapia. Me sentí incómodo y halagado: todo maestro sacrifica la claridad expositiva a cambio de lograr la confusión emocional de sus alumnos. Para mostrar que no había sido indiferente al curso, la chica me regaló un cuaderno de tapas ranuradas, color vino, con hojas amarillas, lo cual sugería que venía de Estados Unidos, donde los borradores se escriben en papel estridente.

Conservé el cuaderno como un talismán de las relaciones no siempre explicables entre maestro y alumno. Al llegar a Yale supe que Harold Bloom impartía un seminario sobre "la originalidad en Shakespeare". Durante un semestre asistí al salón 203 y usé el cuaderno para anotar las contundentes opiniones de Bloom con una letra mucho más pequeña y diáfana que la habitual en mí, como si el dramático

${ }^{3}$ Enumero los subtítulos de las secciones que componen El rey duerme, cuyo fragmento inicial, arriba citado, carece de título, y al cual suceden los siguientes apartados: Un hallazgo; La traducción; El sueño de una sombra, El veneno, las palabras; Del cuaderno; El otro cuaderno. profesor lograra el efecto pedagógico de producir actas de amanuense. (VILLORO, 2008, p.13-14) ${ }^{3}$

Varias líneas de fuerza que habrán de desplegarse a lo largo del texto se dan cita en este comienzo. En primer lugar, la que remite al orden de los "hechos" situados en la esfera pública (firma del tratado de libre comercio, insurrección zapatista), pero los da a leer desde el relato de una experiencia personal, cuyas peripecias fundamentales se enmarcan entre dos 
cuadernos: el que aquí se recibe de manos de una estudiante mexicana antes de partir a Yale, el que entrega una estudiante norteamericana en circunstancias semejantes, aunque no idénticas, concluída la estadía en New Haven y antes de retornar a México, en la primavera de 1994. El primero servirá para anotar las contundentes opiniones proferidas por Bloom, permanecerá olvidado por largo tiempo y será recuperado años después. El acaso (la escritura de Villoro) querrá que el rescate de ese primer cuaderno ocurra inmediatamente luego de haber leído Shakespeare, la invención de lo humano, e inmediatamente antes de dar término a una larga búsqueda que culmina una mañana de 2005, en una librería de Cartagena de Indias, con el hallazgo de la traducción de Hamlet de Tomás Segovia, publicada por la editorial Norma en la serie "Shakespeare por escritores". El otro cuaderno servirá para escribir la crónica del ensayo que leemos: “Como el rey de Hamlet, el [segundo] cuaderno durmió una larga siesta. Volvió a mis manos justo cuando encontré el cuaderno de apuntes. Uno había servido a las leyes del oído. El segundo, como el célebre fantasma, reclamaba otras palabras" (VILLORO, 2008, p.38).

El empleo de objetos de los que cabría predicar su condición transicional en la acepción psicoanalítica del término, dado su carácter de mediadores entre sujeto y mundo, no es inusual en la prosa de Villoro. Tampoco su retorno desplazado en estructuras narrativas que pese a las discontinuidades y saltos temporales suelen valerse de ellos como significantes del trayecto elaborado en (por) la escritura. Aquí, el segundo cuaderno evoca pero a la vez difiere del primero. En 8.8. El miedo en el espejo, esa "crónica en fragmentos" sobre el terremoto del 2010 que sorprendió a Villoro en Santiago de Chile (y en cuyo centro se encuentra un magnífico ensayo literario sobre Heinrich Von Kleist), el objeto transicional será una prenda: el piyama, símbolo de la figura paterna rechazado en la juventud, al comenzar el libro, cuando los huéspedes despavoridos del hotel de Santiago activen ese primer recuerdo; atuendo impuesto al protagonista del cuento infantil escrito para la hija más tarde; regalo enviado por una editora amiga hacia el final del volumen ${ }^{4}$. Se trata de objetos

${ }^{4}$ Sobre esta cuestión véase mi artículo (2016). que circulan, estableciendo itinerarios en los que "los hechos" se enredan con la experiencia del "testigo", expresión cara a 
Villoro para referirse tanto a la función del cronista como a la de varios de sus narradores de ficción.

En El rey duerme, a la constelación de referencias inscritas en el modo de presentar el origen de la invitación a Yale (entrada en vigor del tratado, fantasías de integración al primer mundo irónicamente aludidas por la mención a los "espaldas mojadas" y su correlato intelectual, los "cerebros mojados" ${ }^{5}$, desmentida súbita por el estallido de la rebelión zapatista), cabe agregar dos episodios en los que el orden de los hechos públicos y la experiencia del testigo se reconfiguran mutuamente.

Villoro comienza a dictar su curso y a frecuentar el seminario de Bloom. En las vacaciones de mitad de semestre se aventura en un entretenimiento que "debería estar prohibido para las culturas sin dios de la nieve" (VILLORO, 2008, p.17), el esqui. Se fractura el tobillo, retoma su actividad:

Mientras tanto, mi país se sumió en una tragedia shakespeareana. Luis Donaldo Colosio, candidato del PRI a la presidencia, fue asesinado. El sistema político instaurado desde 1929 se tambaleaba en un drama de intrigas, venganzas, lealtades inciertas.

Mi vida en Yale se revistió de una condición espectral. Subía en muletas al handicup bus y me dirigía a la universidad a hablar sobre la Historia interrogada por la ficción y a oír las interpretaciones de Bloom sobre la dramaturgia del poder y el asesinato. La cubierta color vino de mi cuaderno parecía aludir a los excesos que tanto disfrutaba el Tito Andrónico y a las noticias que llegaban de mi país. (VILLORO, 2008, p.18)

Exactamente en esos "días de nieve y zozobra, el curso de Bloom llega a Hamlet" (Ibidem, p.18). Innecesario decir que la "Historia interpelada por la ficción" encuentra en la dramaturgia shakeaspereana una representación alternativa: el regicidio de la saga dinamarquesa se actualiza en el magnicidio de Donaldo Colosio (uno de los varios que han pautado la historia política de México en el siglo XX); el reino podrido y tambaleante se torna una imagen del PRI, cuyo colapso, mucho

${ }^{5}$ Espaldas mojadas, mojados o wetbacks: in migrantes que cruzan ilegalmente la frontera sur de Estados Unidos, generalmente mexicanos, si bien la expresión se aplica de forma extensiva a todos los latinoamericanos. menos duradero de lo que se imaginó, tendría un desenlace provisorio en las elecciones presidenciales del 2000.

De forma análoga, leer, años más tarde, la traducción del "Hamlet de Segovia" (será preciso volver sobre este enunciado), desencadena la rememoración de una anécdota que conduce otra vez a la revuelta zapatista: 
Revisar la traducción me llevó en forma extraña al alzamiento zapatista. Cinco días después de que Marcos y los suyos se levantaran en armas, salí rumbo a la Universidad de Yale [...] Un año después, en marzo de 1995, me hice cargo de "La Jornada Semanal", suplemento cultural del períodico $L a$ Jornada. El director anterior, Roger Batra, le había ofrecido una columna a Tomás Segovia. Naturalmente, me pareció imprescindible que siguiera con nosotros. Segovia mantenía una correspondencia imaginaria con un alter ego (Matías Vegoso) en la que discurría sobre ética, política, el lugar del intelectual en la sociedad contemporánea. Uno de sus lectores más asiduos era el propio Marcos (VILLORO, 2008, p.26).

Ocurre que el admirado poeta, traductor y ensayista radicado en México durante largas décadas, vive por entonces en un pequeño pueblo de España. Atrasos y desajustes en la correspondencia incitan a Villoro, instado por Alejandro Rossi ("Nadie sabe más de eso que Tomás"), a sugerir la redacción de una columna sobre métrica: "Mi propuesta no le gustó nada al poeta. Él quería hablar de temas significativos para la hora mexicana" (Ibidem, p.26).

No es, sin embargo (aunque tampoco lo descarte), en el pronunciamiento sobre la coyuntura inmediata, donde Villoro identifica el principal legado de Segovia, sino en aquello que constituye el centro neurálgico de El rey duerme; allí, donde la dicción del cronista cede lugar a la lectura sobre los alcances de una traducción que muestra "lo que Shakespeare podría haber escrito en nuestro idioma" (Ibidem, p. 22), que hace del Hamlet de Segovia "una obra maestra" (Ibidem, p. 25) capaz de suscitar un "cruce de realidades":

Ante su traducción experimenté los múltiples cruces de realidades de una obra cuyo sentido se mantiene abierto. En su Hamlet, Segovia revela la eficacia de la metrica para que una lección política llegue sin trabas a nosotros. El dilema entre la voluntad y la conciencia, los mecanismos de la usurpación y la venganza, la economía de las lealtades y las sombras de la traición encuentran acabado desarrollo en esta espléndida rendición de Shakespeare. (VILLORO, 2008, p. 26)

Pero antes de explorar esa zona del ensayo (de la crónica devenida ensayo y viceversa), conviene examinar de cerca algunos detalles del recuerdo fraguado por Villoro sobre su asistencia al seminario de Bloom. 


\section{III}

En Lecciones de los maestros (2011), George Steinter ha propuesto tres escenarios principales o estructuras de relación posibles maestro/discípulo, que han inspirado diversos testimonios religiosos, filosóficos, literarios, sociológicos o científicos: el maestro que destruye al discípulo, el discípulo que tergiversa, traiciona o destruye a su maestro, el intercambio, pautado "por el eros de la mutua confianza e incluso por amor, proceso de interrelación en el que el maestro aprende de su discípulo cuando le enseña" (STEINER, 2011, p.12); un acto "dialéctico", "en el sentido propio de ese término tan denostado" (Ibidem, p.15), afirma el crítico. Steiner no niega la idealización implicada en esta última hipótesis - o dicho de otra forma: no desconoce la premisa foucaultiana según la cual toda enseñanza es un ejercicio, abierto o velado, de relaciones de poder. Pero prefiere no agotar ahí todo el valor y las posibilidades del acto de transmisión.

Considerado desde ese punto de vista, El rey duerme alude a una primera escena de enseñanza elidida, de la cual sólo se le muestran al lector sus reverberaciones. No obstante el cronista ocupe en ella la posición magistral (y el papel protagónico), los efectos son ambivalentes, ya que si tanto las palabras balbuceadas por la joven estudiante como el cuaderno ofrendado remiten a uno de los términos de la relación, la perturbación a la que se asiste es de doble mano ("Ella quería decirme algo que no me dijo... para mostrar que no había sido indiferente al curso me regaló un cuaderno... Me sentí incómodo y halagado"). A esa situación sucede una segunda escena pedagógica retratada con pormenores, en la que la organización espacial arquitectada por el testigo no resulta irrelevante: el seminario de Bloom.

Villoro no integra el primer círculo de la veintena de alumnos inscritos, reunidos en torno a una mesa de roble, sino un segundo "círculo externo" de oyentes, sentados con "las espaldas apoyadas contra la pared" (VILLORO, 2008, p.14).

${ }^{6}$ De acuerdo con Jacques Aumont (1992, p.62), "la mirada es aquello que define la intencionalidad de la visión". La mirada, función indisolublemente ligada a las condiciones de representación ${ }^{6}$, es responsable por la introducción de un distanciamiento que se alía a la posición de escucha y se traduce en un tono enunciativo abiertamente irónico. En lugar 
7 Algunas citas del libro de Bloom que ilustran esa concepción: "Es característico del triunfo shakespereano el hecho de que la obra más original de Occidente, tal vez de toda la literatura mundial, se haya tornado de tal modo familiar que tenemos la impresión de haberla leído antes, aún al encontrarla por primera vez " ( $p$ 503). Refiriéndose a la andadura duvitativa de la pieza y del carácter de su protagonista: "Se trata de la vacilación de la propia conciencia, pues Hamlet inaugura la dramaturgia de la conciencia exacerbada que Pirandello y Beckett sólo reprodujeron, aunque en tono más desesperado, y que Brecht buscó subvertir en vano" (p.504). "Hazlitt profirió algo más que una verdad romántica, con las palabras: "Hamlet somos nosotros". Ciertamente, "nosotros" se extiende/ aplica a Dostoievsky, Nietzche, y Kierkegaard y, más tarde, Joyce y Beckett. Sin duda Hamlet roba para sí la conciencia literaria occidental, apropiándose de los límites del autoconocimiento, impidiéndonos el pasaje que conduce a lo trancendental" (p.514).

"Entre los personajes ficcionales, Hamlet ocupa la posición correspondiente a Shakeaspeare entre los escritores: el centro del centro [...] ¿Sería esa centralidad sólo una construcción de la historia cultural, o estaría implícita en el texto shakespeareano? $\mathrm{Hamlet} \mathrm{y} \quad \mathrm{a}$ a u t o c o n c i e n c i a occidental se han confundido a lo largo de los dos últimos siglos, en el ámbito de la sensibilidad romántica. $\mathrm{Y}$ hay inúmeros indicios de que, cada vez más, la autoconciencia se identifica con Hamlet, inclusive en Asia y África" (p.522) del "provecto anciano", los "tics del sabio venerable" que le dice "child" a cada uno de sus alumnos y asume aires de "profeta": "Bloom hablaba con el fervor de quien encabeza una cruzada. Estábamos ahí para defender el misterioso núcleo de Occidente y oponernos al rapto de los franceses" (Ibidem, p. 15).

El presupuesto del curso, que sería transpuesto a $L a$ invención de lo humano, es conocido: "Shakespeare configuró como ningún otro, la noción que tenemos del individuo" (VILLORO, 2008, p. 15). La agonística implicada en ese planteamiento, formulado inicialmente en La angustia de influencia, también lo es: la "tendencia - a veces homérica, a veces meramente deportiva - a ver la literatura como una liga donde todos luchan entre si y siempre gana Shakespeare" (Ibidem, p.16) ${ }^{7}$. Así como lo es el corolario de semejante postura, la unilateralidad y univocidad interpretativa: "Bloom, que detestava la reducción psicoanalítica de entender a Shakespeare según Freud, aprobaba la lectura del mundo según Shakespeare" (Ibidem, p.16).

Asertivo, apasionado, teatral ("Bloom cerraba los ojos, agitaba la cabeza..."), el maestro lanza asiduamente preguntas a sus alumnos con el objetivo de "mostrar que Shakespeare era capaz de leer su intimidad: - ¿Qué sintieron después de su primer fracaso amoroso? Sabían que ya estaban condenados a volverse a enamorar?" (VILLORO, 2008, p.17). Se trata de intervenciones "dignas de un psicólogo que habla en la radio" (Ibidem, p.17) y que dan lugar dos tipos de situaciones características: por un lado, el discípulo que se desvela estudiando durante días para preparar un comentario y recibe como respuesta un: "Ay, hijo, estás brillantemente equivocado" (Ibidem, p.17); por otro, la alumna hermosa que profiere una "alegre banalidad" y recibe a cambio un: "Pero qué sagaz de tu parte (how shred of you)" (Ibidem, p.17). "Shakespeare había inventado lo humano y en ese momento nadie lo representaba mejor que Bloom" (Ibidem, p.17), sostiene Villoro. La figuración de la escena pedagógica adquiere tintes de sátira, de una sátira que no excluye, inclusive, la referencia metadiscursiva y jocosa al propio mote de la crónica-ensayo:

La respuesta más extraña al espectacular protagonismo de Bloom eran los alumnos con gorra de beisbolista dormidos sobre la mesa. Bloom continuaba, imperturbable, acaso recordando un tema favorito de Shakespeare: la desgracia 
que cae sobre un rey dormido. Ajeno al curso, el inocente beisbolista labraba en sueños su desgracia (VILLORO, 2008, p.17).

\section{IV}

Al paso de comedia satírica suceden las peripecias del primer cuaderno (discreto envío del eros pedagógico), en el cual Villoro anota las "observaciones" que le parecieron "esenciales" durante el seminario de Bloom y que, "dictadas por la espontaneidad, el profesor no siempre incorporó" a su libro (Ibidem, p.18). Olvidado, el cuaderno también duerme una larga siesta para resurgir oportunamente trece años después: "Abrirlo fue escuchar el torrencial énfasis de Bloom. Acababa de leer La invención de lo humano y me pareció que las notas servían de apostillas a esta obra capital" (Ibidem, p.18). A partir de aquí, lo anecdótico (la crónica) se retrae, sin por eso desaparecer, y cede espacio a una dicción ensayística/ meditativa que adopta, en este primer momento, la forma de una suerte de doble marginalia, de complemento (suplemento?) de lo dicho y lo escrito por Bloom.

Distintamente de la estructura de relación maestro/ discípulo irónicamente retratada en el apartado anterior, el recurso a la notación plantea otro orden de problemas: el de su forma misma, el del tipo de enunciación constitutivamente dialógica que supone ${ }^{8}$. Porque ¿quién habla en las notas del cuaderno? ¿El "torrencial énfasis" del profesor, legible en el entrecomillado que remitiría al orden de la cita, de la transcripción de las palabras del otro, y que a partir de un determinado momento cesa aunque las asociaciones desencadenadas por el Hamlet (¿de quién?) continúen? ¿El comentario del testigo que "apostilla", acción que de acuerdo

${ }^{8}$ Sobre las relaciones entre ensayo y teoría bajtiniana, Cf. IOZZIKLEIN y CAVALIARI (2015). También Liliana Weinberg (2017, p. 18) señala el "carácter responsivo" del ensayo, así como el interés de recuperar la categoría de cronotopo bajtiniano para pensar los espaciostiempos organizadores de sentido en dicho género. con el diccionario significa "acotar, interpretar o completar" un texto? Endosar el juego (el simulacro) de la transcripción no cancela el montaje obrado por la escucha. A la celeridad de la voz del profeta no corresponde la mano retardataria del amanuense que registra. ¿Qué selecciona el oído y vierte la mano en el papel? Hacia el final de esta sección, que lleva el deliberadamente ambivalente título de Un hallazgo, se afirma:"este texto deriva del deseo de transmitir los apuntes de Bloom, complementarios de su libro, y del inesperado 
${ }^{9}$ Cito algunos pasajes de las "notas" de Villoro a título de ejemplo: "Shakespeare titula a su obra Julio César más por convención - por acatar la norma de señalar al personaje de mayor rango-que por el papel que desempeña en el reparto. Bruto resulta más interesante. Es un estoico. El estoicismo tiene la fuerza de una religión secular que busca separar la razón de la pasión. Es un claro antecedente de Hamlet. A diferencia de Bruto, Marco Antonio es una figura pasional, epicúrea" (Ibidem, p.19); "Tradicionalmente la crítica ha considerado al personaje de Hamlet una prolongación de Bruto, algo bastante asombroso, dadas las inmensas cualidades de Hamlet. La objetiva astucia de Bruto es mucho menos compleja que el nihilismo de Hamlet" (p.20) "Para el príncipe danés, los propósitos son un fruto que madura por sí mismo; la acción exterior influye poco en ellos. Cuando el fruto cae, sigue siendo propósito, no se transforma en acción. No podemos cumplir nuestro cometido hasta el fin sin enloquecer. Nietzche deriva de esta reflexión" (Ibidem, p.20) encuentro con una nueva versión del clásico" (Ibidem, p.21). En el intervalo que va del deseo hasta la transmisión de lo oído, complementar (suplementar) con respecto a lo que se acaba de leer, y el próximo acontecimiento de lectura, el cronista se ejercita, ensaya operaciones en las que la "voz levantada" de Bloom ("Resulta difícil encontrar un expositor de voz tan levantada como Bloom", Ibidem, p. 37) no deja de reverberar, pero es empujada más allá de sí misma para ingresar en otro circuito de relaciones. Porque si, por un lado, el tono lapidar se mantiene en las sentencias entrecomilladas, por otro, el montaje de las mismas abre camino a un conjunto de cuestiones que la interpretación de Villoro expandirá en dos apartados subsecuentes (El sueño de una sombra y El veneno, las palabras): los dilemas implicados en la relación entendimiento/afecto, intelecto/voluntad, reflexión/acción, las potencias y límites de la palabra ${ }^{9}$. Entre ellos, interferindo en esa reflexión ulterior, se da el "inesperado encuentro" (el hallazgo) del Hamlet de Segovia.

\section{V}

En el prólogo a De eso se trata (2008, p.10), Villoro sostiene que "ensayar es una forma de ejercer la traducción, un intento de volver próximo lo ajeno, buscar que autores de épocas y territorios distantes dispongan de una lengua y una moneda común". La caracterización puede extenderse a la tarea del traductor en sentido estricto, lo cual torna su quehacer una suerte de ensayística asordinada. Y ciertamente define con exactitud la operación clave atribuida a Tomás Segovia: "Su cambio decisivo deriva de pasar de una célebre frase forzada, traducida ("he allí el dilema"), a la lógica interna del idioma: "de eso se trata" (Ibidem, p.25).

Precedida por el "prestigio del rumor", la solución encontrada, pautada por el rescate de una expresión común, puedeconcebirse como la continuación de un diálogo (polémico), cuyo capítulo precedente es otra traducción: "Aunque decenas de traducciones lo facultaban para verter Shakespeare al español, Segovia quiso pepararse con las 862 páginas de $L a$ invención de lo Humano. Ese dilatado boxeo de sombra lo llevó a un combate decisivo" (Ibidem, p.21). Así, en esta versión de los hechos, el Hamlet de Segovia es simultaneamente una respuesta 
${ }^{10}$ A este respecto, $y$ refiriéndose al prólogo escrito por el propio Tomás Segovia, Pedro Serrano (2010, p. 217) afirma: "Segovia despliega todo su conocimiento de métrica y avanza ideas muy firmes sobre la prosodia del español [...] nos hace ver simplemente que el ritmo del español no es como nos lo enseñaron. $\mathrm{O}$ no es sólo así. Hay en la lengua cadencias poéticas a las que quizá nos hemos desacostumbrado, o que el peso del aprendizaje, más que de la tradición, ha querido someter a metros fijos, pero que están ahí, desde el principio de la versificación en español, moviéndose, y que él recupera y ejercita en su versión de Hamlet. En su ensayo Segovia muestra como volvió a aparecer en el verso del siglo $\mathrm{XX}$ tanto en el libre como en el liberado, y demuestra de paso cómo todos los metros de Shakespeare aparecen en los poemas del mexicano Ramón López Velarde. Pero lo más interesante, nos hace saber Segovia, no es porque López Velarde trabajara el verso blanco inglés en español, por supuesto, sino porque esa rítmica que consideramos tan particular del inglés ya existía en nuestra lengua. El español es, como el inglés pero en sentido contrario, una lengua híbrida, mitad latina y mitad germánica"

${ }^{11}$ Las alusiones a la "España peregrina" residente en México como referencia insoslayable para la tradición cultural de ese país son constantes en la escritura de Villoro y solicitan un examen pormenorizado. a las traducciones previas circulantes en español y a "la voz levantada" de Bloom, "combatida", de forma diferida, luego de haberse "preparado" traduciéndola. De cierta forma, las 862 páginas de La invención de lo humano están para el Hamlet de Segovia, como las notas del primer cuaderno de Villoro para El rey duerme. En ambos casos, pese a las drásticas diferencias, Bloom es objeto de contestación y estímulo a la vez.

¿Qué lee Villoro en esa nueva edición de Hamlet que demora tres años hasta llegar a sus manos? La "ilusión de un idioma: las palabras que le convienen a un clásico que no existió en nuestra lengua" (Ibidem, p.24) y que sin embargo, por obra de esa traducción, da la medida de lo que "Shakespeare podría haber escrito en nuestro idioma" (Ibidem, p. 22), "en el lenguaje de Berceo o, de manera más significativa, en el de nosotros mismos" (Ibidem, p.21). Como sostiene Olmos (2017, p. 47), "la traducción de Hamlet al español hecha por Segovia trabaja a favor de una descentralización de la cartografía literaria de Bloom. Las soluciones linguísticas encontradas por el traductor, explica Villoro, consiguen evitar los clichés idiomáticos en los que el texto clásico se ha monumentalizado". E inscriben simultaneamente a Hamlet en otras constelaciones asociativas: el recurso a la "métrica sumergida" imprime a los piés de verso shakespeareanos "la ligereza, afin a nuestro oído, de los de Fray Luis de León o Ramón López Velarde" (VILLORO, 2008, p. 22) ${ }^{10}$; la elección de algunas "expresiones habituales para la generación de españoles que llegaron a México con la guerra civil" (Ibidem, p. 24), a la cual Segovia pertenece, revela que "su versión no es indiferente al idioma de su momento, pero se sitúa en la zona intermediaria donde la traducción rinde sus mejores frutos" (Ibidem, p.24) ${ }^{11}$. El desvío en relación a ciertas expectativas del lector evoca contrastivamente una serie de nombres y de textos literarios de la lengua de destino:

Al traducir de nuevo una obra de la que exiten numerosas versiones previas, Segovia enfrenta las prenociones del lector. La sentencia "el perro tendrá su hora", que dio lugar al título original de Para esta noche, de Onetti, es vertida como "irá a lo suyo el perro". La solución, en modo alguno incorrecta, sorpreende a quienes esperaban la frase conocida [...] Segovia parece haber querido alterar otras expresiones que ya son lugares comunes de la cultura. En su traducción de La invención de lo humano, las últimas palabras de Hamlet son "el resto es silencio". En su versión de la pieza dramática, 
regresa a las habituales "lo demás es silencio", que en nuestra tradición dió título al libro de Augusto Monterroso" (VILLORO, 2008, p.25)

Ocioso señalar la afiliación borgeana del Hamlet de Segovia, en la versión de Villoro. Shakespeare en "nuestro idioma" deviene espacio de resonancias que van de la lírica de López Velarde (un espectro potente en la escritura de Villoro, como lo prueba su novela El testigo), a Jeremías Petrus y el aire fétido de Santa María o la inclasificable biografía fragmentada de Eduardo Torres/autobiografía fictícia de Monterroso. En lugar de la visión imperial y canónica de Bloom en la que el Hamlet de Shakespeare ocupa "el centro del centro" (BLOOM, 2001, p. 522), la deriva hacia otras zonas culturales y otros textos. En el apartado siguiente, intitulado El sueño de una sombra, la radical introspección hamletiana lleva Villoro a pensar "en el verso de José Gorostiza en Muerte sin fin: "Inteligencia, soledad en llamas" (Ibidem, p. 27), dando prosecusión a un juego asociativo que, vale la pena insistir, no excluye por entero la lectura bloomiana ni se propone simplemente invertirla, sino que la fuerza a abirse y a adoptar otra dinámica. La discrepancia en el modo de leer resulta tanto del contenido y procedencia de ciertas asociaciones como de su ley. En ese sentido, si se revisa el capítulo de La invención de lo humano consagrado al "centro del centro", no será difícil hallar varios nombres recurrentes en los textos del propio Villoro: Montaigne, Joyce, Nietzche, Kierkegaard, Goethe, Brecht, están presentes en El rey duerme y también en muchos otros escritos de su autoría. Pero a la estructura jerárquica y derivativa del discurso de Bloom, que hace partir y retornar todo a su centro ("Hamlet se torna el modelo implícito para La genealogía de la moral, de Nietzche. La percepción más shakespeariana de Nietzche es puro Hamlet", BLOOM, 2001, p. 499), Villoro contrapone un tránsito en el que los "cerebros mojados" atraviesan fronteras sin visa ${ }^{12}$. Quizá resida allí, a su vez, una diferencia significativa con respecto a la dicción borgeana, a la que sin embargo Villoro tanto le debe. La discreta pero constante interferencia del cronista/testigo marca de modo indeleble su enunciación e insiste inscribir

${ }^{12}$ Cf. A este respecto La frontera de los ilegales (Villoro, 1995, p. 64-74) e Itinerarios extraterritoriales (Villoro, 2018, p.172-187). algo del orden de la esfera pública (de "los hechos") en su ensayística literaria.

No es fortuito que "revisar la traducción" de Segovia conduzca "en forma extraña al alzamiento zapatista", ni 
${ }^{13}$ Los convidados de agosto se publicó en la revista Nueva Sociedad de enerofebrero de 1995 y muy probablemente exista una publicación previa en el suplemento de $L a$ Jornada. Ese mismo año la crónica es recogida en Los once de la tribu (1995). En 2013 es republicada nuevamente en Espejo retrovisor. que el admirado traductor y poeta desee "hablar de temas significativos para la hora mexicana" en lugar de escribir una columna sobre métrica. Tampoco lo es que la "eficacia métrica" se torne garantia de que "una lección política" sobre "el dilema entre la voluntad y la conciencia" "llegue sin trabas a nosotros". El "cruce de realidades" que Villoro experimenta ante el Hamlet de Segovia remite a una tensión que habita su propia escritura haciéndola transitar, sin visa, de la crónica al ensayo y viceversa. Razón parcial, tal vez, de la presencia de una imagen compartida que asombra tanto este ensayo como sus crónicas sobre Chiapas. Aquí, la observación de Bloom sobre el trato peculiar de Shakespeare con los fantasmas y su fulminante conclusión ("Todo en la obra depende de la respuesta de Hamlet al Espectro", VILLORO, 2008, p. 29) desencadenan, como se señaló, una interrogación acerca de las relaciones entre entendimiento/afecto, reflexión/acción. En Los convidados de agosto, crónica fechada en 1994 (tiempo recuperado "de forma extraña" al leer la traducción de Hamlet), el tercer apartado lleva el elocuente título de El retorno de los muertos vivientes:13

En plena revuelta zapatista, el gobierno referendó la importancia política de los indios muertos. El hallazgo del sarcófago de una reina en el Templo de las Inscripciones de Palenque fue festejado como si el honor de la patria dependiera de las noticias provenientes del inframundo de Xibalbá [...] El mundo de los indios suele ser percibido como una necrópolis fotogénica. Por eso el EZLN hace tanta referencia al retorno de los muertos. Sus pasamontañas vengadores de película de Serie B provienen de un pasado incómodo. El historiador Antonio García de León cuenta que la puerta de un cementerio chiapaneco lleva la siguiente inscripción: "Aquí yacen los muertos que viven en Zapaluta" (VILLORO, 2013, p. 161)

Pese a su diversa procedencia, los "muertos que viven en Zapaluta" parecen suscitar una inquietud semejante a la del espectro hamletiano,

\section{VI}

Refiriéndose al ensayo de Philip Fisher, Thinking About Killing: Hamlet and the Paths Among the Passions (1992), Villoro destaca su sagaz indagación sobre el "papel cultural de los afectos" (VILLORO, 2008, p. 29) en la pieza homónima, aspecto 
relegado a segundo plano por una tradición interpretativa fuerte, de la cual Bloom participa, centrada en las vacilaciones reflexivas del protagonista: "Más que ante una tragedia de la sangre, estamos ante una tragedia de la verdad" (Ibidem, p.34), afirma Bloom en una de las notas transcritas por el escritor.

A esta perspectiva, la perspectiva adoptada por Fisher contrapone una "intrincada red de sentimientos" determinante para la andadura del drama. En esta otra lectura, el asesinato por medio de veneno adquiere especial importancia: “El mundo del veneno opera en secreto y con hipocrecia, [algo] antitético al gran drama público de la venganza" (Ibidem, p. 29). Se trata de un ultraje que autoriza a la víctima a regresar como fantasma, denunciar el crimen y exigir venganza por medio de la sangre (una venganza en cuya ejecución el teatro dentro del teatro, suerte de veneno hecho de palabras depositado en los oídos traidores, no será menos decisivo que las armas, advierte Villoro).

De acuerdo con Fisher, la indiferencia de Hamlet ante la matanza que desencadena se vincula a ese primer agravio antiético, hecho que justificaría su crueldad posterior. El duelo por la muerte del padre se transforma en venganza destituída de culpa ("el hijo actúa como no tuvo derecho de hacerlo el padre"); el príncipe de Dinamarca, en un protagonista "shakespeareano en el arranque y desenlace de la obra", pero "homérico en las muertes intermedias" (Ibidem, p. 29).

Por un lado, entonces, el Hamlet meditativo y sus vacilaciones reflexivas; por otro, el personaje arrebatado por una "intrincada red de sentimientos". Entre ambos, poniendo a prueba una lectura que persevera en la incertidumbre entendida como "ambiguedad irreductible" (GIORDANO, 2005, p.59), el "modo de ver" de Villoro:

Fisher ilumina la intrincada red de sentimientos que determina la obra pero deja fuera el enigma de la razón, decisivo en la configuración de Hamlet. A mi modo de ver, las disquisiciones del protagonista son un obstáculo tanto para pasar al acontecer como para sentir afectos. Pessoa reunió en un verso el sentimiento debilitado por la lucidez: "Lo que en mí siente está pensando". La inteligencia mitiga la emoción al razonarla. A diferencia de Aquiles, Hamlet no busca trascender un dolor por medio de la acción; busca superar su perplejidad ante lo que no supo interpretar a tiempo. 
¿Cómo aceptar que no sospechara lo ocurrido? No es sólo la justicia lo que está en juego, sino la capacidad de entendimiento. El dolor proviene de los límites de la conciencia (VILLORO, 2008, p.30)

Intempestivamente (y cabe recordar aquí la observación del escritor acerca de las Consideraciones intempestivas, de Nietzsche, en Mi padre, el cartaginés (2013, p.195): "En español, lo "intempestivo" alude a lo repentino, lo imprevisto. La palabra alemana sitúa este impulso en un contexto temporal: Unzeitgemäs. Se es repentino respecto a la época"); intempestivamente, el texto adopta una inflexión gramsciana:

Para el trágico príncipe de Dinamarca, la concepción de Gramsci del temple revolucionario (optimismo de la voluntad, pesimismo de la inteligencia") se cumple solo en su segundo aspecto [...]

El padre aparece como fantasma porque fue asesinado mientras dormía. La muerte, país del que no hay retorno, no concede esa visa a todos sus inquilinos [...]

Fisher insiste en el abuso adicional sufrido por el rey: murió sin saber que moría. Su tragedia es la del desconocimiento; la de su hijo, primer nihilista de la cultura, es la del conocimiento. (VILLORO, 2008, p. 30-31)

El drama shakespeareano deviene tensión del intelecto (¿del intelectual?) afectado por la interpelación de los espectros, manutención de una abertura de sentido que proyecta hacia adelante los dilemas concernientes a "la voluntad y la conciencia, los mecanismos de la usurpación y la venganza, la economía de las lealtades y las sombras de la traición", tal como el "modo de ver" del escritor ve y lee en el Hamlet de Segovia. De eso trata, en parte, el "cruce de realidades" del Hamlet de Villoro.

\section{VII}

El otro cuaderno, último apartado de El rey duerme, propone una figuración cruzada y múltiple de la relación maestro/discípulo (tal vez otra variante de la interpelación fantasmal). Allí convergen, en el plano imaginario/imaginado de la crónica/ensayo que se lee, el primer cuaderno recibido por Villoro de manos de una estudiante mexicana, puesto a servicio de la escucha del seminario de Bloom, y el segundo, 
que le entrega una estudiante norteamericana al término de su propio seminario en Yale:

El seminario concluyo en la primavera. Después de los rigores del frío, las plantas que parecían aniquiladas recuperaron su terreno. Yo aún llevaba muletas. Caminaba con esfuerzo entre los jardines, cuando me detuvo una alumna. Dijo cosas vagas y amables sobre el curso que había llevado conmigo, y me regaló un cuaderno (VILLORO, 2008, p.38)

Es este último cuaderno, el único que el lector tiene ante sus ojos en el plano imaginario/imaginado, el que recupera el itinerario que va de las notas/apostillado del seminario bloomiano (puestas en diálogo con la lectura de La invención de lo humano), al hallazgo del "Hamlet de Segovia" (a la lectura que Villoro propone de esa traducción) para arribar, por fin, a La memoria de Shakespeare (BORGES, 1980). La narrativa borgeana posibilita un ejercicio de lectura más que se agrega a los precedentes y refuerza desde la ficción el valor de lo común, del tránsito abierto a espacios y tiempos heterogéneos, sin necesariamente proponerse como conclusión del "viaje" (la pertinencia de la associación ensayo/viaje en este caso es evidente y posee tanto una representación literal - Ciudad de México, New Haven, Cartagena, Chiapas, España -, como remite a los textos visitados). El segundo cuaderno, que inscribe e incorpora al primero, constituye un registro de esa larga jornada en la que el maestro aprende de su discípulo cuando le enseña/muestra lo que escribe en los cuadernos que recibió, a partir de otros maestros que a su vez escuchó, leyó, con los que polemizó, aprendió, y que ahora comparte en el escrito dado a la lectura.

En una notable síntesis de la lección borgeana legible en El rey duerme, Olmos afirma:

Villoro nos recuerda que en el cuento de Borges, un hombre, al ser habitado por la memoria de Shakespeare, descubre que no se trata de la memoria excepcional de un artista sino de las atribulaciones del hombre, es decir, comprueba, con perplejidad, que "escribir como Shakespeare es una desmesura, ser Shakespeare es banal" (36). La universalidad que Bloom le atribuye a la obra de Shakespeare, adquiere en la ficción borgeana un tono menor, ya que no se trata de "la invención de lo humano", sino de lo común del hombre (OLMOS, 2016, p. 47) 
"Un hombre común deja que el idioma fluya. La normalidad del punto del partida exalta el resultado: los cristales surgen de la arena", sostiene Villoro (Ibidem, p. 37). Y agrega: "Shakespeare [como Cervantes] escribió al margen de su posible estatua, sin vigilarse, movido por el placer y la urgencia" (Ibidem, p.37). Leer al margen de la estatua, movido por el placer y por la urgencia, es lo que ensaya El rey duerme.

\section{REFERENCIAS}

ADORNO, T. El ensayo como forma. Trad. Alfredo Brotons Muñoz. In: Notas sobre literatura I. Madrid : Akal Ediciones, 2003. p. 11-34.

AUMONT, J. La imagen. Barcelona: Paidós, 1992.

BENSE, M. "O ensaio e sua prosa”. Trad. Samuel Titan Jr. Revista Serrote, N16, 2014. Disponível en: http://www.revistaserrote. com.br/2014/04/o-ensaio-e-sua-prosa.

BLOOM, H. Shakespeare: The Invention of the Human. New York: Riverhead, 1998.

Shakespeare, la invención de lo humano. Trad. Tomás Segovia. Grupo Editorial Norma: Bogotá, 2001.

Shakespeare, a invenção do humano. Trad. José Roberto O’Shea. São Paulo: Objetiva, 2000.

BORGES, J. L. (1980). La memoria de Shakespeare. In: Obras Completas (1975-1985). Buenos Aires: Emecé Editores, 1989, p.393-399.

FAZIO, S. C. La escritura ensayística como autofiguración: crítica y autobiografía en Efectos personales de Juan Villoro. Taller de Letras, N 41, 2010, p. 21-29.

GIORDANO, A. Modos del ensayo. De Borges a Piglia. Rosario: Beatriz Viterbo, 2005.

IOZZI-KLEIN, A.; CAVALIARI, D. N. A prosificação da cultura e o ensaio criativo do século XX: questões sobre um gênero literário. Bakhtiniana, 10 (1), abril-jamn 2015, p. 104-118. Disponible en: http//dx.doi.org/10.1590/2176-457320863 LÚKACS, G. A propos de l'essence et de la forme de l'essai. In: L Âme et les formes. Paris: Gallimard, 1974, p. 12-33. 
OLMOS, A. C. Ensaio de narradores na literatura latino-americana, 1970-2010. Tese livre-docência, Departamento de Letras Modernas, FFLCH, USP, 2015.

Lecturas errantes y cartografías críticas. In: DHONDT, R.; VANDEBOSCH, D.; WEINBERG, L. (orgs.) Transnacionalidad e hibridez en el ensayo hispánico: un género sin orillas. Leiden; Boston: Brill, 2017, p. 36-48.

SERRANO, P. Hamlet y el verso en español. Alrededor de la traducción de Tomás de Segovia. In: FREIXA A.; LÓPEZ GUIX, J. G. (eds.) Actas del II Coloquio Internacional "Escrituras de la traducción hispánica",2011, 215-225. Disponible en: http//www. traducciónliteraria.org/coloquio2/actas.htm

SHAKESPEARE, W. Hamlet. Trad. Tomás Segovia. Norma: Bogotá, 2002.

STAROBINSKI, J. É possível definir o ensaio? Remate de Males, vol. 32, N 1-2, jan-dez 2011, p. 13-24.

STEINER, G. (2003). Lecciones de los maestros. Trad. María Condor. Buenos Aires: Debolsillo, 2011.

VILLORO, J. La frontera de los ilegales. Anales de literatura hispanoamericana, N 24, 1995, p. 64-74.

Lección de arena: Pedro Páramo. In: Efectos personales, Barcelona: Anagrama, 2001, p. 13-28.

Monterroso: el jardín razonado. In: Efectos personales, Barcelona: Anagrama, 2001, p. 29-41.

Goya y Fuentes, los trabajos y los días. In: Efectos personales, Barcelona: Anagrama, 2001, p. 91-103

El testigo. Barcelona: Anagrama, 2004.

El rey duerme. Crónica hacia Hamlet. In: De eso se trata. Ensayos literarios. Barcelona: Anagrama, 2008, p. 13-38. El Quijote, una lectura fronteriza. In: De eso se trata. Ensayos literarios. Barcelona: Anagrama, 2008, p. 39- 60. Las ataduras de la libertad: Goethe y Las afinidades electivas.In: De eso se trata. Ensayos literarios. Barcelona: Anagrama, 2008, p. 101-116.

Lo que hay en un nombre: el Emilio de Rousseau. In: De eso se trata. Ensayos literarios. Barcelona: Anagrama, 2008, p. 117- 132. 
La fisonomía del desorden: de El pozo a Los adioses. In: De eso se trata. Ensayos literarios. Barcelona: Anagrama, 2008, p. 323-346.

Itinerarios extraterritoriales. In: De eso se trata. Ensayos literarios. Barcelona: Anagrama, 2008, p.172-187.

Los convidados de agosto. In: Espejo retrovisor. México, Seix Barral, 2013, p. 157-172.

Mi padre, el cartaginés. In: Espejo retrovisor. México, Seix Barral, 2013, p.191-214.

WEINBERG, L. El ensayo latinoamericano entre la forma de la moral y la moral de la forma. Cuadernos del CHILA, año 8, N 9, 2007, p. 110-130.

El ensayo en diálogo. De la tierra firme al archipiélago relacional. In: DHONDT, Reindert; VANDEBOSCH, Dagmar; WEINBERG, Liliana orgs. Transnacionalidad e hibridez en el ensayo hispánico: un género sin orillas. Leiden; Boston: Brill, 2017, p. 15-35. 


\section{Resumo}

\section{Notas de leitura sobre El rey duerme}

A frequentação de textos fundadores é uma característica constante da ensaística de Juan Villoro (Ciudad de México, 1956). Em El rey duerme, crónica hacia Hamlet (2008), o escritor põe em cena uma singular aproximação à peça homônima de Shakespeare. O artigo propõe uma leitura desse texto, em torno do seguinte conjunto de questões: a) as interferências e tensões existentes entre crônica e discurso ensaístico; $b$ ) as várias figurações da relação mestre/discípulo; c) o diálogo polêmico instituído com a interpretação de Harold Bloom (Shakespeare: The Invention of the Human, 1998) e as estratégias textuais implementadas para essa finalidade; d) o deslocamento interpretativo proposto a partir do Hamlet traduzido ao espanhol por Tomás Segovia (2002) e do último conto de Jorge Luis Borges (1985).

Palavras-chave: releituras de Hamlet; crônica, discurso ensaístico e tradução; Juan Villoro. 


\begin{abstract}
Reading notes on $\mathrm{El}$ rey duerme

Visiting founding texts is a constant characteristic of Juan Villoro's (Ciudad de México, 1956) essay writing. In $\mathrm{El}$ rey duerme, crónica hacia Hamlet (2008), the writer brings a singular approximation to Shakespeare's homonymous play. The article proposes a reading of this text around the following set of issues: a) the existing interferences and tensions between chronicle and essay; $b$ ) the various configurations of the relation master/disciple; c) the polemic dialogue instituted with Harold Bloom's (Shakespeare: The Invention of the Human, 1998) interpretation and the textual strategies implemented for this end; d) the interpretative displacement proposed starting with Tomás Segovia's (2002) Spanish translation of Hamlet and Jorge Luis Borges's (1985) last short story.
\end{abstract}

Keywords: Hamlet; chronicle essay and translation. 